\title{
ESTÉTICAS CURVAS PARA UNA REVOLUCIÓN ARTÍSTICO-FEMINISTA
}

\author{
Alejandra Bueno de Santiago \\ Universidad Nacional de Educación (Ecuador). Dpto Educación Artística \\ Universidad Politécnica de Valencia. Dpto. Escultura
}

\section{Resumen}

El principal problema que sigue existiendo en los feminismos es la falta de unión que ha derivado de una crisis epistémica y de conocimiento. Esto ha sido trasladado al campo artístico, pero con menores rivalidades, lo que acontece en estos momentos es una reflexión del conocimiento y de las prácticas artísticas culturales, que comienza por cuestionar el todo, para quedarse en un análisis fragmentado, ya que la inclusión gestáltica solo propiciaría un nuevo orden social exclusivo y fijo. Se comienza por el análisis de la estética, cualidad intrínseca al pensamiento humano, después lo humano, concepción historicista basada en una figura hermética y patriarcal, lo histórico, un campo de batalla en el que la mujer ha sido el elemento reproductivo, el espacio público, lugar de encuentro y de generación de conocimiento y así sucesivamente. En esta propuesta se establece una serie de relaciones conceptuales y prácticas que tratan no de eliminar viejos paradigmas culturales, sino más bien tratan de criticar los viejos y promover nuevas relaciones que busquen re-conocer en lo consabido, que se practiquen a sí mismas, lo que Rian Lozano llamó "prácticas culturales anormales". Para tratar el tema en profundidad y analizar un caso real, se propone como práctica cultural anormal el Festival Internacional de Cine feminista, Fem Tour Truck.

\section{Palabras clave: FEMINISMO; ANORMAL; ESPACIO PÚBLICO; COLECTIVO; CONOCIMIENTO SITUADO}

\section{AESTHETIC CURVES FOR AN ARTISTIC- FEMINIST REVOLUTION}

\section{Abstract}

The main problem that still exists in feminisms is the lack of union that has resulted from an epistemic crisis and knowledge. This has been transferred to the artistic field, but with less rivalries, what happens at the moment is a reflection of knowledge and cultural artistic practices, which begins by questioning the whole, to remain in a fragmented analysis, since the gestalt inclusion would only propitiate a new exclusive and fixed social order. It begins with the analysis of aesthetics, intrinsic quality to human thought, then human, a historicist conception based on a hermetic and patriarchal figure, the historical, a battlefield in which the woman has been the reproductive element, the public space, place of encounter and generation of knowledge and so on. This proposal establishes a series of conceptual and practical relations that try not to eliminate old cultural paradigms, but rather they try to criticize the old ones and to promote new relations that seek to re-know in the known thing, to practice themselves, what Rian Lozano called "abnormal cultural practices". To discuss the subject in depth and to analyze a real case, the International Women's Film Festival, Fem Tour Truck, is proposed as an abnormal cultural practice.

Keywords: FEMINISM; ABNORMAL; PUBLIC SPACE; COLLECTIVE; TERRORIST QUESTIONING

\footnotetext{
Bueno de Santiago, Alejandra. 2017 . "Estéticas curvas para una revolución artístico-feminista". AusArt 5 (1): 91-101 D0I: 10.1387/ausart.17793
}

\section{AUSART}




\section{INTRODUCCIÓN}

Por mucho tiempo el conocimiento ha sido generado en las calles, desde Grecia en el ágora hasta el siglo pasado en las plazas, en la actualidad todavía los líderes políticos manifiestan sus ideologías desde los espacios comunes, pero los lugares de intercambio se están trasladando al plano virtual. Desde el Festival Internacional de cine Feminista, se rescatan las virtudes del conocimiento abierto y compartido en red, pero también sus falencias, ya que no es un espacio transitado por todos, cuando el espacio de la calle, sigue siendo el lugar que se habita sin distinción de género, raza, sexo, ideología... es el lugar del encuentro simbólico que en estos momentos está siendo desvirtuado y está en desuso. El análisis del espacio público comienza hablando de su privatización y su análisis como escenario de control, asumido consciente e inconscientemente por todos. En sus inicios se instaura como un lugar de libre expresión, política, estética, social, económica, etc., pero la cantidad de representaciones estereotipadas marcan una brecha en su propia definición, dejando lo que antes era público en un campo de batalla por la auto representación y el adoctrinamiento, donde la figura de la mujer es un reclamo de miradas y es objeto de significantes que desfiguran su propia naturaleza, alienándola al consumo y a la subordinación. En la calle nos podemos manifestar y podemos vivir políticamente, pues el cuerpo es político y por lo tanto la vida también lo es, es un proceso estético y político que tiene como objeto transmitir su propia existencia.

\section{DECOLONIZANDO EL ESPACIO}

El hecho simbólico de recuperar las calles en actos artístico-culturales en manifestaciones públicas como el festival Fem Tour Truck', es un acto de rebeldía ante la institución, que se basa en la hibridación de personas en un mismo espacio con el objetivo de visibilizar la otredad, el ser marginal hermanado en sororidad y discutiéndose a sí mismo. La producción cultural es también un hecho político y en concreto las prácticas anormales, se resisten a seguir 


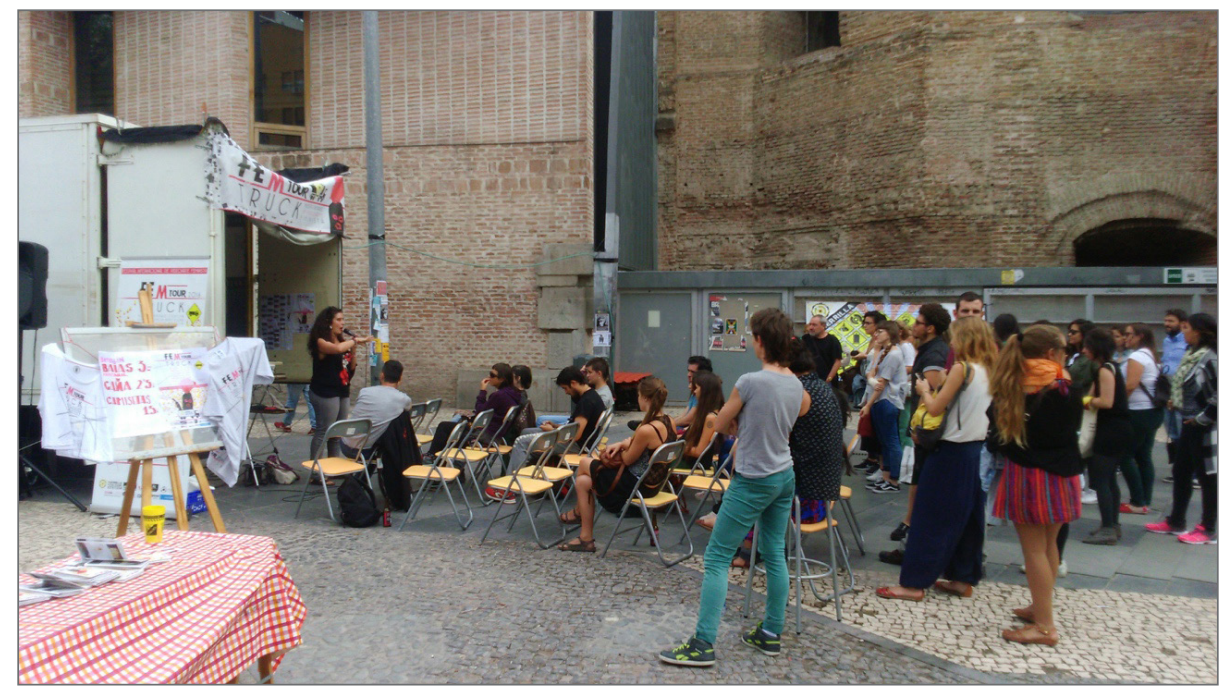

Taller de Irantzu Varela en Fem Tour Truck en Madrid, 2016.

la norma que marca el discurso artístico hegemónico y además cuestionan la objetividad del relato histórico y rechazan las bases del desinterés estético-artístico (Lozano 2010, 20). Este festival se basa primordialmente en generar un análisis de las culturas visuales desde lo teórico y desde lo práctico, haciendo especial énfasis en esta segunda parte, la performatividad.

El festival Fem Tour Truck, recoge una serie de videocreaciones, performances, cortometrajes y documentales que ponen sobre la mesa el problema de género, pero desde una perspectiva que no dramatiza, sino que posiciona a la mujer en un estado de poder que antes no tenía, no hay que confundir con una supremacía de la mujer, el hembrismo, sino con una postura de mujer empoderada que toma las riendas, que se queja, que lucha y que crea conciencia mediante su cuerpo político. En el contenido que recoge el festival se pueden ver videos de más de 30 países diferentes, de todos los continentes, y todos ellos simbolizan a la mujer desde el empoderamiento, muchos de ellos juegan con el humor para representar situaciones violentas. Cada uno de estos videos que posteriormente han sido expuestos en las plazas de 8 ciudades diferentes, son un buen campo de estudio para el análisis de la cultura visual, un nuevo análisis que empieza a estudiar lo anormal alejándose de lo normativo, ya que cualquier estudio anterior ha sido realizado desde el análisis de documentos patriarcalistas. El estudio de esta "antigua" cultura visual nos ha servido para entender de qué manera se estaban construyendo los imaginarios, ya que las representaciones visuales no son una inocente forma de narrar el mundo, sino 
que intrínsecamente llevan consigo la cualidad de ser un "productor de sentidos, estableciendo y conservando los valores estéticos (...), la cultura visual abre un gran mundo de intertextualidad, donde imágenes, sonidos, delineaciones espaciales son leídas desde y a través unas de otras" (Rogoff 2002, 24). Es por ello que existe la necesidad de promover y difundir en los espacios de conocimiento aquellas representaciones que cambien el paradigma heteropatriarcal de representación y así como dice Judith Butler, podremos comenzar a considerar lo no visible como nuevos lugares de producción de conocimientos alternativos (Butler 2002). Este lugar no visible hace referencia tanto al lugar olvidado de los espacios públicos como el cuerpo de la mujer.

El lugar de la cultura visual independiente y anormal se puede entender como un lugar intermedio que escapa del control (Mirzoeff 2002, 189), tanto como por su carácter disidente como su geolocalización que habita en los márgenes, lugar de concurrencia de las minorías. Estos bordes cada vez corren más el peligro de institucionalizarse ante el intento de nombrar y jerarquizar cualquier movimiento o práctica artística. El más allá es un espacio de exploración sin definición en el que todo concepto y práctica tiene cabida, y donde la política también sucede sin dejar de lado a la estética.

En el movimiento feminista la estética ha sido fuertemente criticada ya que su afinidad con la belleza ha cosificado mucho al cuerpo de la mujer. La estética ha sido entendida como la belleza, pero en el momento que esa estética se vincula a la producción cultural adquiere la dimensión de política, sobre todo en esta época de crisis epistemológica, de identidad y de sentido, que se ha visto influenciada por la avalancha de imágenes y su matiz teórico-conceptual y de significantes varios, por ello la estética no es atemporal y ha de ser revisada ya que implica una forma de ver y entender el mundo.

En otra época la dimensión política de la estética no habría sido entendida, ya que implicaba una relación con el goce de mirar y no con cómo mirar. Desde los primeros análisis de la cultura visual se entiende que ésta es un productor de miradas y es entonces con una postura consciente cuando nos dedicamos a revisar la historia pasada y la actual para proponer nuevas prácticas culturales y artísticas.

El papel del artista actual es el de generar nuevos pretextos y el de analizar hasta qué punto las prácticas contribuyen a instaurar un conocimiento autorizado. Si partimos de que el origen de ese conocimiento se daba en las plazas, a través de la conversación y el intercambio de saberes, si trasladamos esa 
práctica en la actualidad podemos ubicarla en internet con el intercambio de imágenes, pero también en las calles y plazas que siguen siendo el espacio de reunión por antonomasia pero que se extiende en esta dimensión de hiperrealidad $^{2}$ anunciada ya por Baudrillard ([1978] 1987), hasta las redes sociales.

No es casual que este festival busque la actuación en las plazas, ya que trata de recordar el carácter de acogedor de eventos históricos, para dar lugar a otra serie de hechos históricos que siguen sin autorizarse. La palabra ágora viene del griego áyopá, asamblea, de áycípw, "reunir", y antiguamente era la burguesía quien debatía con las autoridades y en la actualidad este libre derecho a la expresión puede ejercerse sin restricciones. Por medio de esta recuperación de la plaza que tantas connotaciones tiene trata de apropiarse de esas características para dar veracidad a su propia práctica artística a favor de los otros. Con respecto al análisis del espacio público, Carrión (2007) expresa su carácter difuso e indefinido ya que juega a dos bandas, a favor del poder y en favor del aprendizaje y la libertad. Son varios los teóricos que lo definen desde un ámbito y el otro, Rabotnikof (2005) en la tercera de sus definiciones, le atribuye la característica de lo común, lo que está abierto y es aceptado por todos: lo apropiado por todos, pero no privatizado por nadie en beneficio personal. Pero la definición más acertada es la que hace Lefebvre ([1974)] 2013): no es ni neutro ni apolítico, sino un producto social construido y disputado por actores sociales, políticos y privados que se adjudican su producción. Ante esta realidad no queda otra postura que la de jugar en esta batalla de la representación como un actor más, que desde la creación y representación colectiva trata de re-conocer nuevos imaginarios para hacerlos presentes, es la historia de contar para ser contados. Aunque en ocasiones esta necesidad de contar y nombrar se vuelva en contra, con esa obsesión de enmarcar cada práctica y concepto en una corriente. Al hilo de este drama de contar y medir Oteiza expresa lo siguiente: "la geometría enseña a medir y la arquitectura a contar. El hombre midiendo siempre la naturaleza y la naturaleza contando siempre. El hombre inmovilizando, ordenando siempre la geometría. La naturaleza viviendo, enseñando siempre al hombre a vivir, a contar. A veces el arte tiene que ocuparse más de medir lo que está contando que de contar. $U$ sucede que cuando está todo casi medido, faltan muchas cosas que contar" (Oteiza [1963] 2007).

La esfera pública es el lugar para ejercer la pedagogía de la alteridad (Carrión 2007), ya que es un espacio de aprendizaje donde los cuerpos monstruosos ${ }^{3}$ pueden hablar entre ellos y donde tiene cabida para expresarse. Las ciudades son el escaparate de la sociedad, pero también son cabinas ambulantes de 
vigilancia del sexo-género, producto de la heteroespacialización por sus usos y des-usos, ante nuestros ojos, una política de producción de subjetividadescorporalidades que trascienden el espacio público y privado. En la ciudad tal y como está diseñada, habita un único ser, el heterosexual, y éste se altera cuando el cuerpo lésbico, trans, intersex, homosexual y queer rompe el encierro de la norma (Perneth 2017).

\section{LOS CUERPOS OTROS}

En este espacio de creación, Fem Tour Truck, todos los cuerpos salen a la calle para performar su cuerpo, en talleres, debates, conciertos, performances, y visionado de video creaciones, irrumpiendo la normalidad y alterando el orden, tratando de desestabilizar la representación normativa. Para Isaac Joseph (1988) el espacio público también representa un espacio de aprendizaje y para Habermas ([1962] 1994) de libertad, pero no dejaremos de olvidar la noción de lugar de control de la que habla Foucault (1980). En todo caso es el lugar de acción de los monstruos y del artista, y como decía Rancier todo artista es un performer, es como un político aristotélico, y sus acciones son también institucionales y sociales. El espacio urbano es el lugar ideal para estos performers que crean tanto su mundo como el nuestro, donde intercam-

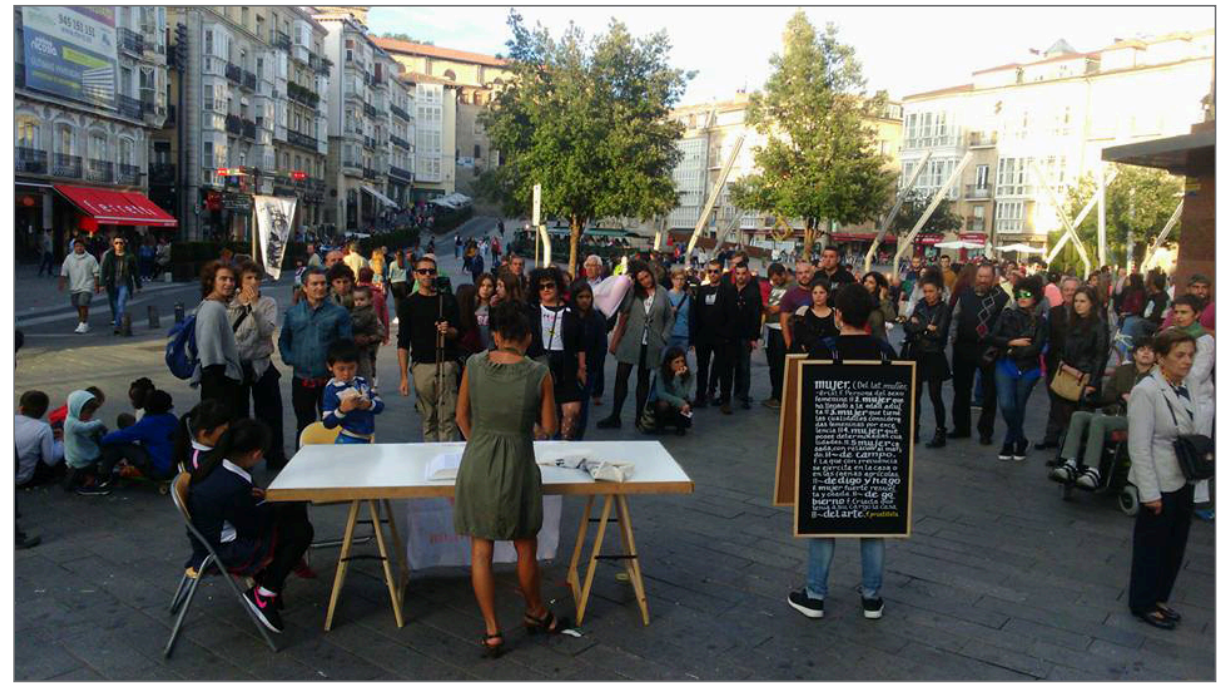

Performance de Nerea Lekuona en Fem Tour Truck Vitoria, 2016. 
bian significados desde un trabajo colectivo, disociando el binomio público-privado, sacando el cuerpo (privado) a las calles, la política (privada) y trasladando lo público a los hogares, el conocimiento.

Recuperar el espacio público para las manifestaciones de la alteridad constituye una toma de poder sobre algo ya olvidado, el derecho a la asociación y a la identidad. Este derecho al espacio público se inscribe en el respeto a la existencia del derecho del otro al mismo espacio, porque no solo necesitamos un espacio donde encontrarnos sino un espacio donde construir tolerancias (Carrión 2007).

Según la definición que da Lozano de su propio concepto, las prácticas anormales constituyen el terreno donde es posible acceder al conocimiento del otro y del uno desde una perspectiva compleja de negociaciones e intercambios constantes. Estas prácticas no tienen por qué estar ligadas con el espacio público pero sí que tienen un carácter a-institucional, en el marco del festival Fem Tour Truck a su paso por Europa ha tenido lugar en las calles de Madrid, Bilbao, Barcelona, Valencia, Vitoria, Covilha y Lisboa, pero a su paso por Latinoamérica ha sido realizado en instituciones culturales y universidades que no hacen disminuir su carácter anormal, sino que potencian su carácter alter-mundializador gracias a su capacidad de negociación intercultural.

En todo este camino no ha tratado de buscar una definición que agrupe a los movimientos feministas, pues si no hay aún una definición como tal es porque se escapa del movimiento social para convertirse en una cuestión política y de interese económicos. Desde la base del feminismo, la lucha por la equidad común sin distinción de color, raza, ideología..., ha sobrepasado sus límites y como corriente política abarca todas las posturas posibles, desde el marxismo hasta el anarquismo, y lo que pretendía ser un acto de sororidad en ocasiones se contradice y se enemistan dejando al público desconocedor desconcertado. Al tratar el feminismo en las calles, en el marco de un festival apolítico, la lucha y el mensaje se hacen más legibles, en un espacio donde interviene lo lúdico, concepto fundamental para el aprendizaje y lo social, tratando internamente como decía Haraway (1997) de hacer un conocimiento situado, aquel que nace de una crítica a la epistemología feminista del punto de vista feminista.

El festival no habla de belleza, sino de bellezas, donde no se toma en cuenta la Gran Teoría de Tatarkiewicz (1972), una teoría general y objetiva de la belleza que implica las características armónicas, las proporciones áureas y el ordenamiento de las partes de los objetos, sino que parte de una postura mucho 
más subjetiva que ha sido traducida en la teoría del gusto que pasa del ámbito objetual al perceptual, pero como hemos dicho anteriormente, cada cosa que intenta ser medida, normalizada y convertida en teoría pierde su carácter dinámico y totalizador. El gusto hace referencia a lo subjetivo, no hay duda que es individual, pero esta visión se rompe cuando se cuestionan las localizaciones de la mirada "la trampa de la visibilidad axial empezó a ser desbordada por las visibilidades laterales emergentes" (Mirzoff 2002). Sin excluir ningún gusto el repertorio de representaciones de la selección de videos está hecho desde una percepción que integra el gusto y las miradas de dos continentes diferentes y cuatro visiones distintas de cada uno de los integrantes del jurado, Blasco Moscoso, Pedro Soler, Lidia Navas y Alejandra Bueno de cuatro identidades diferentes, con lenguajes y localizaciones diferentes.

\section{MIRADAS OTRAS DE VER}

Fem Tour Truck no trata de rescatar los trabajos de mujeres artistas como se ha venido haciendo, sino que rescata la mirada trasversal en un intento de normalizarla desde el espacio simbólico de la calle, donde el control ejercido desde lo visual dialoga con este nuevo discurso. Los problemas que derivan de esta mirada trasversal, no se relaciona con la idea de feminidad sino con la falsa interpretación que se da del arte y de la estética, que se entienden desde el paradigma clásico y obsoleto de belleza. Esta alteración de la mirada trasversal "no supone un trabajo de destrucción de viejos paradigmas (...), deberá activar una dimensión propositiva" (Lozano 2010). Esto quiere decir una propuesta crítica y creativa capaz de generar alternativas al conocimiento autorizado. En este trabajo de prácticas anormales se trabaja desde la puesta en común de las diferencias y de los fragmentos, a modo de diálogo intercultural.

Se trata de huir de la mirada recta que analiza y critica Monique Witting (1992), olvidando aquel concepto de pureza propio de la cultura clásica, no solo en cuanto a representación se refiere sino también en lo que, a creación y producción, olvidando las normas. En esta crítica de la estética normal o la idea del straight mind se propone la estética curva, una estética que, si admite variaciones e hibridaciones y que propone el encuentro de lo imposible en lugares imposibles, no normaliza los juicios, ni el gusto, porque de querer institucionalizarlo dejaría de serlo. Esta estética propone la disolución de la norma y admite a las personas curvas. Para aquellos que necesiten de lo político, propone una 
postura más anarcofeminista que marxista. El poeta Español Jesús Lizano escribe un poema dedicado a las personas curvas que resulta inspirador, en las siguientes líneas se puede leer el fragmento final de este poema:

No me gustan las cosas rectas

ni la línea recta:

se pierden

todas las líneas rectas;

no me gusta la muerte porque es recta,

es la cosa más recta, lo escondido

detrás de las cosas rectas;

ni los maestros rectos

ni las maestras rectas:

a mí me gustan los maestros curvos,

las maestras curvas.

No los dioses rectos:

¡libérennos los dioses curvos de los dioses rectos!

El baño es curvo,

la verdad es curva,

yo no resisto las verdades rectas.

Vivir es curvo,

la poesía es curva,

el corazón es curvo.

A mí me gustan las personas curvas

y huyo, es la peste, de las personas rectas.

El artificio de lo estético está siempre adscrito a formas ideológicas dominantes de la sociedad de clases moderna, así como en realidad, de toda una nueva forma de subjetividad humana apropiada a ese orden social (Eagleton 2006). Es importante revisar el concepto de humano desde las teorías feministas ya que se basa en el origen cristiano de hombre y mujer, que se perpetúa hasta nuestros días. Dentro del festival el análisis socio-cultural que se genera va desde lo general a lo particular, desde lo humano, lo estético, la belleza, la historia, el conocimiento, la representación visual y el cuerpo. Judith Butler (2006) en un ejercicio de repensar la vida e instaurar nuevos modos de ver y sentir propone "rehacer lo humano", desde el plano académico y activista, pero olvida el valor del papel del arte en la formalización de los horizontes compartidos. Es decir, el artista, en su papel crítico y autocrítico tiene el deber de repensar y ahondar en lo ya sabido e institucionalizado para generar un nuevo pensamiento abierto. 
Para volver atrás y mirar la historia desde arriba también hay que performarla, vivirla, y la revolución feminista está construyendo su historia a través de la lucha, así como se han creado todas las historias, disolviendo la jerarquía del género que hoy en día es un concepto caduco. El arte en su papel de mediador, de medio y de agente es el que va a visibilizar esta nueva cultura visual y va a propiciar el cambio desde sus prácticas anormales. Para finalizar, en palabras de Rian Lozano (2010): "Encontramos la posibilidad de trazar un camino que parte de la norma del gusto relacionada con las prácticas institucionales y disciplinadas, rumbo a un gusto por lo anormal, conectado al contrario con demandas políticas no estandarizables".

\section{Referencias}

Baudrillard, Jean. (1978) 1987. Cultura y simulacro. Traducción Antoni Vicens y Pedro Rovira Barcelona: Kairós

Butler, Judith. 2002. "What is Critique? An Essay on Foucault's virtue". En The Political: Readings in Continental Philosophy. London: Basil Blackwell. http://eipcp.net/transversal/0806/ butler/en/print

Butler, Judith. 2006. Deshacer el género. Traducción de Patricia Soley-Beltrán. Barcelona: Paidós

Carrión Mena, Fernando. 2007. "Espacio público, punto de partida para la alteridad". En: Espacios Públicos y construcción social. Hacia un ejercicio de Ciudadanía, Olga Seovia, ed. Santiago de Chile: Ediciones Sur

Eagleton, Terry. 2006. La estética como ideología. Traducción de Germán Cano y Jorge Cano. Madrid: Trotta

Habermas, Jürgen. (1962) 1994. Historia y crítica de la opinión pública. Versión castellana de Antonio Doménech. México DF: Gustavo Gili

Haraway, Donna. 1998. "Situated knowledges: The science question in Feminism and the privilege of patriarcal perspective". Feminist Studies 14(3): 575-99

Joseph, Isaac. 1988 El transeúnte y el espacio urbano. Traducción, Alberto Luis Bixio BarceIona: Gedisa

Lefebvre, Henri. (1974) 2013. La producción del espacio. Traducción de Emilio Martínez Gutiérrez. Madrid: Capitán Swing

Lozano de la Pola, Riánsares. 2010. Prácticas culturales anormales: Un ensayo alter-mundializador. México DF: UNAM

Mirzoeff, Nicholas. 2002. "The subjet of visual culture". En: The visual Culture Reader. London: Routledge

Oteiza, Jorge. (1963) 2007. Quosque tándem...!: Ensayo de interpretación estética del alma vasca. Reimpr., Amador Vega (coord.). Alzuza, Navarra: Fundación Museo Jorge Oteiza, 2007 
Perneth, Kelly. 2017. "Cuerpos mostruosos-infecciosos". En: El género en cuestión: miradas multidisciplinares sobre lo normativizado, Alejandra Bueno de Santiago, coord., 38-46. Manta, Ecuadro: Mar Abierto

Rabotnikof, Nora. 2005. En busca de un lugar común. El espacio público en la teoría política contemporánea, México DF: UNAM

Rabotnikof, Nora. 2010. “Discutiendo lo público en México”. En: ¿Qué tan público es el espacio público en México?, Mauricio Merino Huerta, coord., 25-56 México DF: Fondo de Cultura Económica

Rogoff, Irit. 2000. Terra Infirma, Geography's Visual Culture. London: Routledge

\section{Notas}

${ }^{1}$ El festival Fem Tour Truck, es realizado por Alejandra Bueno con el apoyo de la plataforma cultural Guerrilla Food Sound System, fundada por Rubén Castillejo y Alejandra Bueno en el 2013. Fem Tour Truck nace en el 2016 y contó con el apoyo de la Bienal Mirada de mujeres y el Gobierno Vasco con el programa de Fábricas de Creación, Etxepare y Eremuak. Es un festival internacional e itinerante que hasta el momento se ha realizado en Bilbao, Vitoria, Madrid, Barcelona, Valencia, Covhila, Lisboa, Portalegre, Quito, Guayaquil, Manta, Cuenca, Badajoz, Edimburgo, Bogotá y Manizales.

${ }^{2}$ El Hiperrealismo es la realidad llevada al extremo de convertirse en ficción. Para Baudrillard el hiperrealismo es el fin de la representación, donde el signo elimina la referencia, pues este adquiere, por medio de la recontextualización, un valor más elevado a aquel que tenía como representación.

${ }^{3}$ Kelly Perneth habla de los cuerpos monstruosos-infecciosos, a todos aquellos cuerpos que deshabitan la norma y que son infecciosos para espacio urbano. 